\title{
Lindell Bromham: Reading the story in DNA
}

\author{
OUP, 2008, PB, 368 pp, ISBN 978-0-19-929091-8
}

\author{
Sara L. Goodacre
}

Published online: 10 February 2009

(C) Springer-Verlag 2009

What do washed up whale blubber and a stinking plant have in common? The answer is that both are cited by Lindell Bromham in her new book, 'Reading the story in $D N A$ ', as intriguing illustrations of how molecular data can help us understand how the world around us came to be.

Stepping in to the world of evolutionary genetics and molecular evolution can be a daunting process. 'Reading the story in DNA' aims to be a starting point to understand how these sorts of data can be used by the modern biologist. On the eve of the widespread use of 'new generation' sequencing technology and the tidal wave of molecular genetic data that this seems likely to generate, the arrival of this book seems particularly timely.

One of the strengths of the book is that it provides a lively and accessible account not just of the techniques and theory underlying the field of molecular genetics and evolution, but of the histories behind some of the people who have contributed to the current state of knowledge. It is interesting to see descriptions of a diverse range of people whose stories illustrate to the reader the important tenets that they must grasp presented in such a way that they are likely to remember. I would strongly recommend this text to supervisors wondering how best to enthuse-rather than confuse-a new student in the general subject area, while at the same time conveying the complexities and difficulties that evolutionary geneticists continue to face without oversimplifying ongoing debates.

The book does not set out to be a reference text book; instead it includes both technical sections and case summa-

S. L. Goodacre ( $\square)$

Institute of Genetics, Queen's Medical Centre,

University of Nottingham, Nottingham NG7 2UH, UK

e-mail: Sara.goodacre@nottingham.ac.uk ries-from giant globsters to stinking plants-and the narrative describes the wide range of different sources of information that should always be considered by an evolutionary biologist-from ancient fossils to the smallest piece of DNA. Each section contains useful primary reference sources with a careful summing up at the end and good use is made of both forward and backwards referencing within the book so that each individual section can flow freely. Equations are avoided, and while I think that these might sometimes have been instructive, there certainly is a place for the view that explanation by words alone allows for greater accessibility of ideas to students of a non-mathematical persuasion. The interspersion of the narrative with technical sections and case studies does occasionally make it slightly tricky to follow the main text, but I think that the inclusion of the latter is more than worth it and I suspect that after an initial read through, it is the interjecting sections to which the reader will return on a regular basis.

The excellent chapter on tree building (Chap. 7) neatly demonstrates the value of suggesting this text as a book to read in its entirety, rather than as a reference book, because of the gentle way in which information is built up from the first chapter through to the last. Chapter 7 relies on preceding sections of the book and clearly sets out the certainties and uncertainties inherent in the tricky task of generating a tree, dealing with both the practical difficulties involved in generating molecular data as well as their computational analysis.

The book ends with a challenge to the reader to take up their own research mantle, ending with 'Good luck and have fun'. Perhaps this embodies the attitude that we should hope to inspire in all our students, equipped with knowledge of who and what has gone before, and with excitement at the thought of what their own contribution might be. 